International Journal of

MULTILINGUAL EDUCATION

\title{
MULTILINGUAL EDUCATION
}

ISSN: (Print) ISSN 1987-9601

(Online) E ISSN 1512-3146

Journal homepage: http://multilingualeducation.org/

\section{Some Interesting Internet Resources and Activities for Teaching a Foreign Language (English) Online}

\author{
Khatuna Gelashvili \\ Ivane Javakhishvili Tbilisi State University, \\ Tbilisi, Georgia. \\ Email: khatogela@hotmail.com
}

To cite this article: Khatuna Gelashvili (2021) Some Interesting Internet Resources and Activities for Teaching a Foreign Language (English) Online:

International Journal of Multilingual Education, \#19, pp. 188-194.

DOI: $10.22333 /$ ijme.2021.190022

To link to this article: https://doi.org/10.22333/ijme.2021.190022 


\title{
Khatuna Gelashvili
}

Ivane Javakhishvili Tbilisi State University, Tbilisi, Georgia

\section{Some Interesting Internet Resources and Activities for Teaching a Foreign Language (English) Online}

\begin{abstract}
Is online teaching worse than the one in the classroom? No, it is different and sometimes even better, only teachers should be aware of available resources and techniques in order to use peculiarities of online teaching effectively. We should know when and how to apply them and how to select the most effective ones for specific tasks to achieve the best results in teaching. The aim of this conference presentation is sharing some effective webpages, activities and techniques that work better while teaching online and that have been tested in my online teaching English and Georgian as second languages. The participants will practically get familiarized with some of the resources. More specifically, the presentation will cover the following topics:

- some websites for presenting new material, practicing it and testing it

- some websites and the activities or techniques for teaching, revising and activating vocabulary

- some websites for correct pronunciation

- some websites for getting students' feedback
\end{abstract}

The participants of this presentation will not only theoretically learn the presented resources, teaching activities and techniques, but also they will immediately use the most effective ones for online teaching at the conference session. They will be able to select some new resources of their interest and use them in their teaching practice.

Keywords: online teaching, the second/foreign language, English as a Foreign Language (EFL), sharing experience, online teaching resources

\section{Introduction}

The purpose of this paper is to prove that online teaching is not worse than the one in the classroom, it is different and it takes different skills, resources and techniques from a teacher. I would like also to share some of the best online teaching resources and activities that work the best while we teach online. They are the ones I have tested in my online teaching practice.

Online teaching has become an integral part of our education, especially since 2020, when universities and schools in Georgia started online teaching due to the pandemics but $I$ have been teaching Georgian as a second language online earlier, since 2006. All the time as a reflective teacher interested in multimedia teaching I have been researching respective resources. Since March 2020 my research has become much more active in order to motivate stressed students, get them more involved in learning and even to have better results than when teaching in the classroom. 


\section{Methods}

The methods of my unofficial research vary:

- I have attended numerous TEFL, TOT, training sessions and conferences on educational technologies

- I have constantly been searching for some new websites, apps and techniques while planning a new lesson

- I have a diverse classroom or online teaching/teacher training and experimenting experience

\section{Results}

As a result of the above-mentioned research I have gathered plenty of electronic and internet resources, which have proved to be really effective in practice.

The websites and activities I have discovered are listed below according to their teaching functions.

1. The websites for presenting new material, practicing, production (PPP) and testing it

- $\quad$ www.quizizz.com

(e.g. https://quizizz.com/admin/quiz/5cad6f401f3b67001b3c7a5a/english-proverb)

This site is the most practical, effective, entertaining, productive and convenient in my experience. A teacher can find a ready lesson on any topic and share the slides on the screen to present new material. When students have already learnt it, the teacher can find a quiz on the same topic and the whole class can practice it in the "preview" mode. The teacher may comment for clarity. This mode is very productive and less stressful for students, when they are at a practicing stage.

The same or similar quiz can be given as a live test, when we would like to test students and their rating is displayed on the dashboard. It is this dashboard and immediate results, as well as limited time frame (defined by a teacher) that makes Quizizz.com very convenient for testing. It can be used for both formative and summative testing. A teacher does not need to spend hours on checking students' tests as their results are transparently and immediately displayed on the screen.

A teacher can give the same quiz as homework too and see the report of students' results later.

Quizizz.com has plenty of ready-made lessons and quizzes on various EFL and other topics or other subjects and it makes the site very handy as a teacher can find an appropriate test in 
the last minute to fill a gap or to practice different grammar, vocabulary, etc. Creating a new quiz or lesson is also very easy.

The colorful design, sound/music, fun memes and the bonus system makes the site truly multimedia one. All these provide students' complete concentration and involvement.

It is worth noting that quizizz.com has an app too.

- www.baamboozle.com

(e.g. https://www.baamboozle.com/game/55556)

This site has numerous ready-made lessons and games too. A teacher just needs to find a right grammatical or lexical topic on the website in the "games" section or he/she can design a new test himself/herself.

I use the "play" mode. I divide the class in two teams and they compete with each other giving a group answer, when it is their turn. Students are much more cautious before they give final answer in fear of losing points. On top of it the program sometimes orders to swap, to lose or to gain points for no reason. It causes a lot of emotions. The sense of unexpectedness and competitiveness between the teams provides full involvement, teamwork and the need to know the topic consciously. This way a lesson turns into a mixture of a game and learning/practicing. A teacher should help with facilitation and analysis.

- wordwall.net

(e.g. https://wordwall.net/resource/3286388/subject-and-object-questions)

This is one more site, where we can find plenty of ready activities on a topic of our interest or we can design one. Different fun modes make the test more enjoyable. Wordwall.net can be used for grammar, vocabulary, etc. The different function, for what I use this site the most frequently is speaking. We may find or create a list of questions or topics in the form of wheel of fortune or cards. All students randomly get their question or topic to speak about. It is ideal for breaking ice at the first lesson. The site can be used so that all students, even passive ones take part in a lesson.

\section{- www.quizlet.com}

This is a site of flashcards, frequently accompanied with a native-speaker's pronunciation. Quizlet is especially effective for vocabulary learning or revision. I use it for checking a class's or a student's knowledge. On one side of flashcards we can see a definition/translation or 
picture of the word/phrase and if they know it, they can immediately check by clicking the flashcard. The program repeats the word, to which a student gives a wrong answer until it is learnt.

Quizlet has different modes: flashcards, learn, write, test, gravity. Like quizizz, it can be used for testing as well. In "live" mode students can be tested as individuals or as teams of up to four players. Quizlet is convenient for self-study and homework. Except from the site its respective app is also available too.

- www.listenaminute.com

(e.g. https://listenaminute.com/?fbclid=IwAR1361NENmqOv4lj3g6ovCYumA_ rktuED5EHWJ3IMWKc_P4e_54HFw6UHSI)

This is the site that provides a huge amount of diverse topics each containing a small text, respective audio and exercises on reading, writing, spelling, speaking, etc. Students can select a desirable topic.

It can be used as a warming-up, a gap-filler, an additional activity on a taught topic, a homework, a vocabulary booster, etc.

\section{The activities or techniques for teaching, revising and activating vocabulary}

Vocabulary learning or revision techniques, games and activities online differ from face-toface ones. These are the ones I have been successfully using:

\section{Hangman on Zoom whiteboard}

This is the activity, which takes no preparation, a teacher can select a word from a certain wordlist, e.g. from a covered unit and draws as many dashes on the Zoom whiteboard as there are letters in the word. At the same time he/she draws gallows. Students try to guess the word letter by letter, if the teacher draws all body parts or "hangs" them before they can guess the word, the students lose. If someone wins, she/he thinks a word.

\section{Making a collective dictionary in Google.doc}

A teacher / a student shares a document in Google.doc, where all students enter new vocabulary items, respective definitions/ translations and examples from the recently covered text. Each group is responsible for one paragraph only. Eventually they get a dictionary in a 
short time. This website enables teachers and students to correct one another's' mistakes in the file.

\section{Writing a story}

Breakout rooms in Zoom give us a wonderful chance for pair and group or team work. The way we can use the technique is e.g. writing a story collectively.

A teacher displays a set of words/phrases and asks the students to write a story. Students should use all of the vocabulary items in any sequence in it. The teacher may additionally specify the genre of the story, e.g. comedy, detective, etc. This activity can be done in Google.doc or MS Word in breakout rooms.

Another option of group story- writing is when we give the middle part of a text and students should write the beginning and the end of it.

PowerPoint can give additional effects to a presentation or a story, if students accomplish a text with pictures, special effects, audio, etc. They can write it on the topic they have just finished.

Story-writing is useful for developing cohesion and coherence skills, spelling, punctuation, usage of new words in a context, etc.

\section{Dubbing a video}

This activity takes a lot of preparation, teamwork and creativity. It should be given to a group of students as a homework or a project. There are several options how to do it depending on what we would like to achieve:

1. A group of students watch a video story with subtitles (e.g. this https://www.youtube.com/watch?v=8D4nRi2juq0) and they should get ready to read the lines of a narrator and other characters as close to the original as possible having turned off the volume.

2. Students may change the text making it funny or just different and role play it in front of the class again having the volume turned off.

3. Students get a short extract of a dynamic passage with a lot of facial expressions and context but without sound and they should dub the video improvising texts according to the contents.

These activities are not only fun but very productive too in order to elicit a lot of vocabulary and grammar, practice correct pronunciation and appropriate intonation. 


\section{The websites for correct pronunciation}

\section{- Google Pronunciation}

(e.g. https://www.google.com/search?q=entrepreneur+pronunciation)

The quickest way to check correct pronunciation is to type any word in Google together with the word "pronunciation" and we get normal and slow ways of pronouncing the word correctly, also American and British versions of it.

\section{- howtopronounce.com}

This site not only provides the correct pronunciation, but also it enables learners to practice it recording their voices.

\section{- https://www.naturalreaders.com/online/}

There are many "text to speech" sites and apps but this website is one of the best ones. It enables us to paste or upload even whole texts, then we select a native speaker's voice, a male's or female's, British or American accent (other accents are for fun or research, I suppose), we can also speed up or slow down reading.

This website can be very useful for students before a presentation, learning a new text, etc.

- www.google.doc

This site has tools/voice typing function, which enables users to dictate a text and it will be typed. This function can be used by a teacher to check students' pronunciation. They say some words and if Google.doc "understands" and types correctly in the document, this pronunciation is acceptable.

\section{The website for getting students' feedback} www.surveymonkey.com

(e.g. https://www.surveymonkey.com/create/preview/?sm=PDglFG047L2wgsIwJByo OXmh5_2B9jm1HfEh9U84yymbE_3D\&tab_clicked=1)

Zoom reactions is the simplest way to get all students' feedback at a lesson. But for more comprehensive survey, poll or any other feedback www.surveymonkey.com is very useful. It 
is simple, user-friendly and it gives statistics to see the full picture of our teaching, students' attitude, preferences, choices, recommendations, etc.

\section{Conclusion}

To summarise, online teaching can be much more colorful, entertaining, motivating and productive than typical classroom teaching. All the above-discussed resources, activities and techniques serve this purpose. Hopefully, other English and not only English teachers will find them interesting, productive and useful and they will benefit from my research.

\section{References}

Gelashvili, Kh. (2021). August 28) \#GYRSA pedagogebi saqartvelodan, presentation "Sharing of some effective multimedia, methods and activities for online teaching a foreign language" delivered at the online conference "Online education and digital transformation during the pandemic" organized by GYRSA, August 28, 2021 https://drive.google.com/drive/folders/1PyVB_zX3GlQRD3gLXydbJTwmyQw9WdT O?fbclid=IwAR3-

18z8KSoF8nB5AWJD6W7SgLV7sQG1FCR3Gzff42AaRrEQMwWDpfnsuFQ

Spratt, Pulverness, Williams, (2012) - The TKT (Teaching Knowledge Test) Course, Mary Spratt, Alan Pulverness, Melanie Williams, Cambridge University Press, 2012.

http://www.quizizz.com

https://wordwall.net

https://wordwall.net

https://www.baamboozle.com

https://www.google.com

https://www.google.doc

https://www.listenaminute.com

https://www.naturalreaders.com/online/

https://www.quizlet.com

https://www.surveymonkey.com

https://www.utube.com 